\title{
In Vitro Clonal Propagation of Nardostachys jatamansi: A Traditional Himalayan Medicinal Plant
}

\author{
Hem Chandra Pant ${ }^{1} \cdot$ Harsh Vardhan Pant ${ }^{2} \cdot$ Arun Kumar $^{1} \cdot$ Himani Tomar $^{1} \cdot$ Manish Dev \\ Sharma $^{1} \cdot$ Naveen Gaurav ${ }^{1 *}$ \\ ${ }^{1}$ Department of Biotechnology, Shri Guru Ram Rai University, Dehradun, Uttarakhand, India \\ ${ }^{2}$ Department of Chemistry, Shri Guru Ram Rai (P.G.) College Dehradun, Department of Biotechnology, \\ Uttarakhand, India \\ *Corresponding Author: naveensri17@gmail.com
}

Received: 27.6.2021; Revised: 26.8.2021; Accepted: 5.11.2021

CSociety for Himalayan Action Research and Development

\begin{abstract}
Plant tissue culture method has an impressive technique for Investigation and Explains basic and applied problems in plant biotechnology field. Micropropagation has played a vital role in the rapid multiplication of many plants species. The nodal explants and shoot tip of $N$. jatamansi inoculated in MS medium (Murashige and Skoog) contain different types concentrations of PGRs (Phytohormones) at various frequencies for the optimization of growth quality for shoot bud Induction, shoot proliferation and micro rooting in plant. The perfect shoot induction takes place in the concentration of BAP + IBA $(2.0 \mathrm{mg} / 1+1.5 \mathrm{mg} / 1)$ multiplication of nodal explants and shoot tip in the combination lower concentration of $\mathrm{BAP}$ and $\mathrm{KN}(2.0 \mathrm{mg} / 1+1.5 \mathrm{mg} / 1)$ This combination proved best for multiple shoot formation. Half strength (1/2) of the MS medium containing NAA and BAP $(1.5 \mathrm{mg} / 1+1.0 \mathrm{mg} / 1) \mathrm{in}$ combination was most useful for rooting in plant. Well developed rooted micro shoots were smoothly removed for the culture flask and dipped in $70 \%$ ethanol for 2 min and then washed with running tap water for 5-10 min to remove media for the root and transferred to small plastic cups carry cocopeat, garden soil and sand (2:2:1) and produce healthy growth in ex-vitro conditions.
\end{abstract}

Key Words: Nardostachys jatamansi, Nodal explants, MS medium, Micropropagation, PGRs - Plant Growth Regulators

\section{Introduction}

Medicinal plants used almost in all countries and cultures as a source of secondary metabolites \& medicine. Medicinal plants have important role in the health care systems and does natural resource constitute one of the potential sources of bioactive chemical entities for drug development. Traditional medicinal uses of plants offer valuable indication to such drug development. It is estimated that about $60 \%$ population of the word and $80 \%$ population of growing nation depend on classical medicine for the key of fitness (Denbath et al., 2006). In Vitro Clonal propagation method have become more used in commercial plant tissue culture and agriculture field for the multiplication of 
medicinal plants and highly Endangered species plant. (George and Sherrington, 1984; Dodds, 1991; George, 1993; Das et al., 1996). Nardostachys jatamansi is a tiny, small, hairy, perennial, rhizomatous, herbaceous, rare and most antique species belong to the family Valerianacae (S.Airi el al., 2000). Plant is distributed from Himalayas to Pakistan, in India including Jammu and Kashmir, Himachal Pradesh, Uttarakhand, Sikkim to Nepal, Tibet and China which show a historical medicinal uses in Ayurvedic medicine (Evans et al, 2008). Nardostachys jatamansi commonly known as Spikenard,and take place naturally in the high regions of Himalayas at the height of 11 to17 thousand feet (Vijay et al., 2012). It is commonly known as Indian nard, balchar or spikenard, Jatila, Bhootjat Nalanda, Jatamansi, Nardin or Muskroot (Bakhru et al., 1993). The rhizomes of the plant is used in historic medicines in distant medicinal order related to nerve, digestive, circulatory and works as an effective memory booster and improves learning and cognitive skills (Yang et al, 1996).

Rhizomes and roots of the plant consist of number of chemical constituents such as essential oil which is pale yellow in color and has pleasant odour (Disket et al, 2012). It is rich in coumarins and sesquiterpines (jatamansone, valerone, jatamansol, jatamansic acid, dihydrojatamansin, nardosatchone) (Alam et al, 2016). Some other constituents are jatamol A, jatamol, nardosinone, spirojatamol, patchouli alcohol, jatamansinone, oreoseoloi, oroseolol, oreselone, valeranal, seselinnardostachyins, seychelane, sugar, resins, starch etc (Thorat et al, 2009).

The In Vitro tissue culture technique is now being used globally for the multiplication of medicinally important plant species and also responsible to produces large numbers of secondary metabolites (Gaurav et al., 2018). Plants rhizomes (commonly called, roots) used in India as a medicine and also in pharmaceutical industry for making different types of valuable drug (Wealth of India, 1997). N. jatamansi is mostly propagated through seeds and vegetative parts. It has a long juvenile phase of 3-4 years followed by a short reproductive phase. Seed germination in natural condition is also very low (10-20\%; Nautiyal et al. 2003). Therefore, in vitro technique can be a good alternative and contributed significantly for mass propagation and conservation of this critically endangered species. Plant rhizome essential oil (spikenard oil) is used in 26 ayurvedic preparations (Nadkami et al, 1954) this species is traditionally employed in the treatment of disorders and is a natural brain nervine tonic and a memory enhancer, which has calming, peacefulness and relaxation features. It is an endangered ayurvedic medical herb had been 
used since the ancient times for many medicinal purposes (Chopra et al., 1954). The trading of Nardostachys jatamansi reflects the high levels of commercial exploitation that also occurs with other Himalayan herbs like Aconitum ferox, Picrorhiza kurrooa and Swertia chirata (Mulliken et al., 2000).

\section{Materials and Methods}

Explant source: The explants used for the investigation were nodal explants and shoot tip, healthy $N$.jatamansi plants were selected for tissue culture experiment. The mother plants were collected from the different Uttarakhand region of Kumaun (pithoragarh,munsyari and bageshwar dist).After collection of the plant from the different region, the plant is potted in small pots for further grow. Very young three months old plant was used as explants in this experiment. The selected ex plant carefully removed from mother plants for tissue culture studies. The explants size reduced up to $2-3 \mathrm{~cm}$ length and $1-2 \mathrm{~cm}$ width at base.

Surface Sterilization of Explants: For the surface sterilization of $N$. jatamansi the nodal segments and shoot tip were first cut to $2 \mathrm{~cm}$ in length and washed under running tap water for 5 to 10 minutes with 1 drops of Tween-20 emulsifier. And then treated in $0.1 \%(\mathrm{w} / \mathrm{v})$ bavistin for 25 minutes and to remove phenolic compounds for the explants Antioxidants treatment was given by using $0.2 \% \quad(\mathrm{w} / \mathrm{v})$ polyvinyl pyrollidone (PVP) for 15 minutes. finally nodal segments was carried out in laminar air flow with $70 \%$ ethanol for 2 minutes followed by Antimicrobial mercuric chloride $0.1 \%(\mathrm{w} / \mathrm{v})$ for 1 minute, Ex plant were rinsed seven times with sterile distilled water to remove traces of Clorox completely. Nodal segments were dissected into $1.5 \mathrm{~cm}$ in length prior to transfer in full strength semi-solid Murashige and Skoog media.

Culture medium and conditions: During present investigation only MS medium was used, For shoot Induction and Multiplication of Explants, while for all the rooting experiments half strength MS medium was taken with 3\% $(\mathrm{w} / \mathrm{v})$ sucrose and $0.4 \%(\mathrm{w} / \mathrm{v})$ agar supplemented with different concentration of PGRs in both the experimental set ups. $\mathrm{pH}$ of the M.s media fix up 5.8 earlier to adding agar by apply $0.1 \mathrm{~N} \mathrm{HCl}$ and $0.1 \mathrm{~N} \mathrm{NaOH}$. After adding different concentration of growth hormones, about $30-50$ $\mathrm{ml}$ of media was transferred into each culture flask. The medium was autoclaved $(1.05 \mathrm{~kg} \mathrm{~cm}-$ 2, $\left.121^{\circ} \mathrm{C}, 20 \mathrm{~min}\right)$ and all the cultures after inoculation were maintained at $25 \pm 2^{\circ} \mathrm{C}$ in the culture room under a 16 hours illumination (40$50 \mu \mathrm{mol} . \mathrm{m}-2 \mathrm{~s}-1)$ bring by white types of tubes.

\section{Shoot regeneration and Multiplication:}

Phytohormone used: For shoot induction MS medium $+(\mathrm{BAP}+\mathrm{IBA})$ in different concentrations was taken and also in combination BAP with Kinetin for shoot 
Proliferation. After shoot induction in plant different combination concentrations of cytokinins $\mathrm{MS}$ medium $+(\mathrm{BAP}+\mathrm{KN})$ were taken for further proliferation and growth of the plant. Culture medium without PGRs (Phytohormone) served as controls in all cases. Data was recorded regularly after 10-15 days of culture.

Rooting of shoots: Phytohormone used: In Root formation, shoots $2-5 \mathrm{~cm}$ lengthy were take out and then shift to $1 / 2$ strength of MS media take in various concentrations of BAP and NAA in various combinations. Rooting number shoot and length of roots Data shoot were noted after 18-22 days of culture. For shooting as well as rooting, the cultures in the same medium but without PGRs served as controls.

Acclimatization of plantlets : Well developed rooted micro shoots of $N$. jatamansi were carefully taken out of the culture medium and smoothly dipped into $70 \%$ ethanol for $2 \mathrm{~min}$, washed with distilled water for 5 to $10 \mathrm{~min}$ to remove medium gel for the root and then transferred to plastic cups containing different mixture of soil and covered with polythene bags. Three different types of soil mixture were tried for acclimatization process.

Statistical analysis: The data on percentage of shoot or root response, their average number and length were recorded at regular intervals. The Explants were injected culture flask in the three types of replicates of each Experiment. Explants Treatment were done three times for the multiplication stage and twice for the rooting stage. Roots of the plants numbered and length measure after 16-18 days of culture media. Statistics is calculate by the ANOVA. Means of the data were analyzed by the Duncan's test to find out the implication of differences.

\section{Results}

Plant tissue culture always has linked with microbial contamination. To decontaminate the explants, we have used different types of sterilizing agents $\left(\mathrm{HgCl}_{2}\right.$ and $\left.\mathrm{NaOCI}\right)$. Sterilization Process (surface) along 70\% ethanol for 1 to 2 min proceed by $\mathrm{HgCl}_{2}(0.1 \%$ of Tween 20 for 5 to $10 \mathrm{~min}$ ) (Leifert et al, 1992, Monokesh Sen et al., 2013). The sterilization technique used for plant, surface sterilization method in the present study produced $90 \%$ contamination free cultures and PVP was used to prevent browning of the medium due to presence of phenolics compounds in the plant (Staba et al, 1980).

Shoot bud induction: Different concentrations of cytokinin (BAP) and auxins, (IBA) were taken in combinations for shoot bud regeneration in the plant. Shoot bud development was most effect by the concentrations and different types of phytohormone were used in this experiment finest result was obtained in MS medium adding 
with BAP $(2.0 \mathrm{mg} / \mathrm{l})+$ IBA $(1.5 \mathrm{mg} / \mathrm{l})$ (Table-1).

In this type of phytohormone combination $66 \%$ of plants formed shoots. The best shoot bud developed in the concentration 2.0 BAP +1.5 IBA $7.50 \pm 0.29 \mathrm{~cm}$ with average number of the shoots and $2.77 \pm 0.09 \mathrm{~cm}$ average length of the shoots. The next perfect induction was raised on ms medium containing BAP $(1.5 \mathrm{mg} / \mathrm{l})+\mathrm{IBA}$
$(1.0 \mathrm{mg} / \mathrm{l})$ in which the standard numbers of the induction shoots $6.50 \pm 0.29$ with the mean length of the shoot $2.45 \pm 0.03 \mathrm{~cm}$. (Janhvi mishra et al., 2017). It was also reported that the BAP + IAA concentration in the mixture produce impressive outcome but not preferable than BAP+IBA concentration.

Table 1: Effect of different concentrations of BAP (6-benzyl amino purine) and IBA Indole butyric acid in MS medium for shoot induction of $N$.jatamansi.

\begin{tabular}{cccccc}
\hline $\begin{array}{c}\text { S. } \\
\text { No. }\end{array}$ & $\begin{array}{c}\text { MS medium BAP + } \\
\text { IBA mg/L }\end{array}$ & $\begin{array}{c}\text { Days } \\
\text { taken to } \\
\text { shoot } \\
\text { regenera } \\
\text { tion }\end{array}$ & $\begin{array}{c}\text { Percentage of } \\
\text { Responses }\end{array}$ & $\begin{array}{c}\text { No. of Shoot per explant } \\
\text { (Mean +SE) }\end{array}$ & $\begin{array}{c}\text { Average length } \\
\text { (Mean +SE) }\end{array}$ \\
\hline 1. & $0.0+0.0$ & 0.00 & 0.00 & 0.00 & \\
2. & $0.5+0.5$ & $18-21$ & 33 & $1.50 \pm 0.29$ & $1.15 \pm 0.03$ \\
3. & $1.0+0.5$ & $16-19$ & 41 & $4.00 \pm 0.71$ & $1.92 \pm 0.14$ \\
4. & $1.5+1.0$ & $15-18$ & 58 & $6.50 \pm 0.29$ & $2.45 \pm 0.03$ \\
5. & $2.0+1.5$ & $12-14$ & 66 & $7.50 \pm 0.29$ & $2.77 \pm 0.09$ \\
6. & $2.5+2.0$ & $11-15$ & 50 & $3.50 \pm 0.29$ & $2.17 \pm 0.08$ \\
7. & $3.0+2.5$ & $12-15$ & 41 & $1.50 \pm 0.29$ & $1.05 \pm 0.05$ \\
\hline
\end{tabular}

10 replicates/analysis; frequently thrice, Means are determine by the Duncan's multiple range tests at the expressive level of $5 \%$

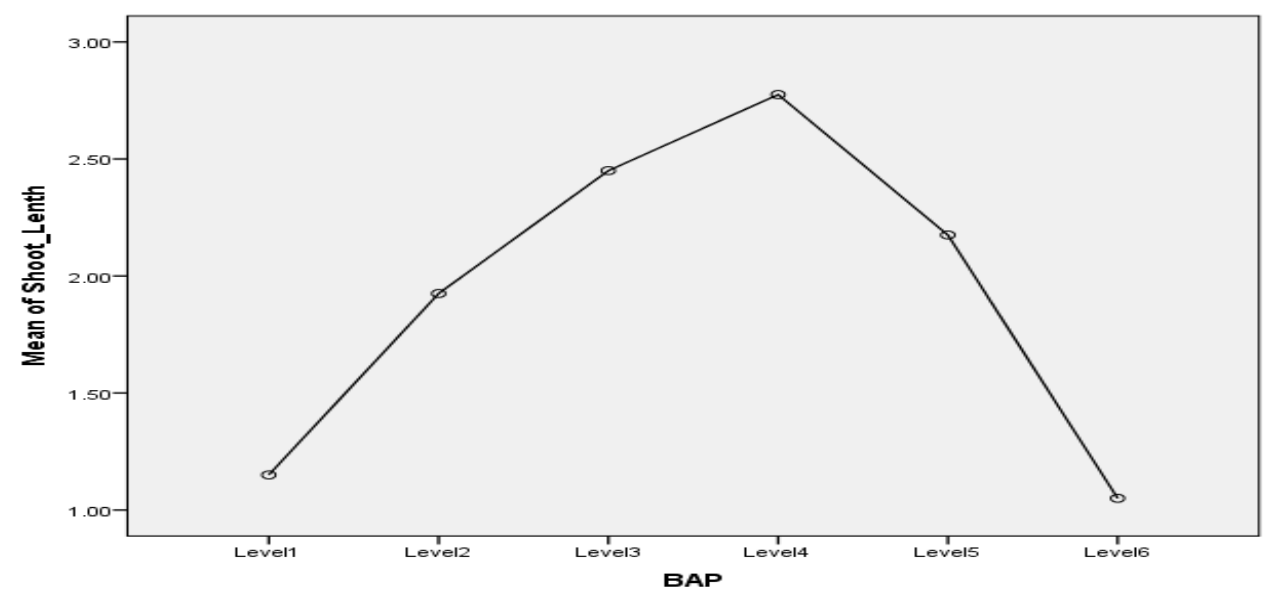

Fig1: Effects Phytohormones (Level 1 to level 6 is the different concentration of BAP 0.5 to $3.0 \mathrm{mg} / \mathrm{l}$ and IBA 0.5 to $2.5 \mathrm{mg} / \mathrm{l}$ ) on shoot bud induction of $N$.jatamansi 
Shoot Multiplication and proliferation: In vitro methods have also been employed for achieving faster rates of multiplication (Khoshkhui and Sink et al, 1982, Kornova and Michailova et al, 1994). The tissue culture method is a widely applicable for study, selection and propagation of plants. The potential of the cells to grow and develop into multi cellular organisms is known as cell totipotency (Wetzstein and $\mathrm{He}$ et al, 2000). It can be employed for large-scale propagation of disease free clones and gene pool conservation. Multiplication shoots of the plant details were noted on the all explants after 14-15 days of culture; on MS medium carry different type concentrations of growth regulators BAP and kinetin. Number of the multiply shoots were noted from the culture media. Largest number of $11.25 \pm 1.11$ shoots per explants and with mean length of the shoot $3.63 \pm 0.18 \mathrm{~cm}(\mathrm{p} \leq 0.05)$ was reported on MS medium carry $2.0 \mathrm{mg} / \mathrm{l} \mathrm{BAP}+$ $1.5 \mathrm{mg} / \mathrm{l}$ kinetin (Table. 2). This indicate the plant needed cytokinins to multiplication maximum number of the shoots per explants. Anterior research shows on other N.jatamansi species is improvement of proliferation of shoots media containing BAP (Purohit et al., 2012, Chandra et al. 2006). MS medium containing with the concentration $2.0 \mathrm{mg} / \mathrm{l} \mathrm{BAP}$ and 1.5 $\mathrm{mg} / \mathrm{l}$ kinetin is perfectly for shoot multiplication.

Table 2: Effect of different concentrations of 6-benzyl amino purine (BAP) and 6-furfuryl amino purine (Kinetin) in MS medium for shoot initiation, multiplication and shoot growth in $N_{\text {.jatamansi. }}$

\begin{tabular}{cccccc}
\hline S.No. & $\begin{array}{c}\text { Ms medium BAP }+ \\
\text { kinetin } \mathbf{M g} / \mathbf{L}\end{array}$ & $\begin{array}{c}\text { \% of } \\
\text { Responses }\end{array}$ & $\begin{array}{l}\text { Days taken to } \\
\text { shoot } \\
\text { multiplication }\end{array}$ & $\begin{array}{c}\text { No. of Shoot per } \\
\text { explant } \\
\text { (Mean } \pm \text { SE) }\end{array}$ & $\begin{array}{c}\text { Average length } \\
\text { (Mean } \pm \text { SE) }\end{array}$ \\
\hline 1. & $0.0+0.0$ & 0.0 & 0.00 & 0.00 & 0.00 \\
2. & $0.5+0.5$ & 41 & $15-20$ & $2.25 \pm 0.25$ & $1.28 \pm 0.05$ \\
3. & $1.0+0.5$ & 50 & $15-20$ & $5.50 \pm 0.65$ & $1.95 \pm 0.12$ \\
4. & $1.5+1.0$ & 66 & $11-14$ & $7.75 \pm 0.25$ & $2.85 \pm 0.06$ \\
5. & $2.0+1.5$ & 75 & $10-12$ & $11.25 \pm 1.11$ & $3.63 \pm 0.18$ \\
6. & $2.5+2.0$ & 41 & $10-12$ & $5.50 \pm 0.65$ & $2.38 \pm 0.06$ \\
7. & $3.0+2.5$ & 25 & $10-15$ & $1.50 \pm 0.29$ & $1.15 \pm 0.03$ \\
\hline
\end{tabular}

10 replicates/analysis; frequently thrice, Means are determine by the Duncan's multiple range tests at the expressive level of $5 \%$

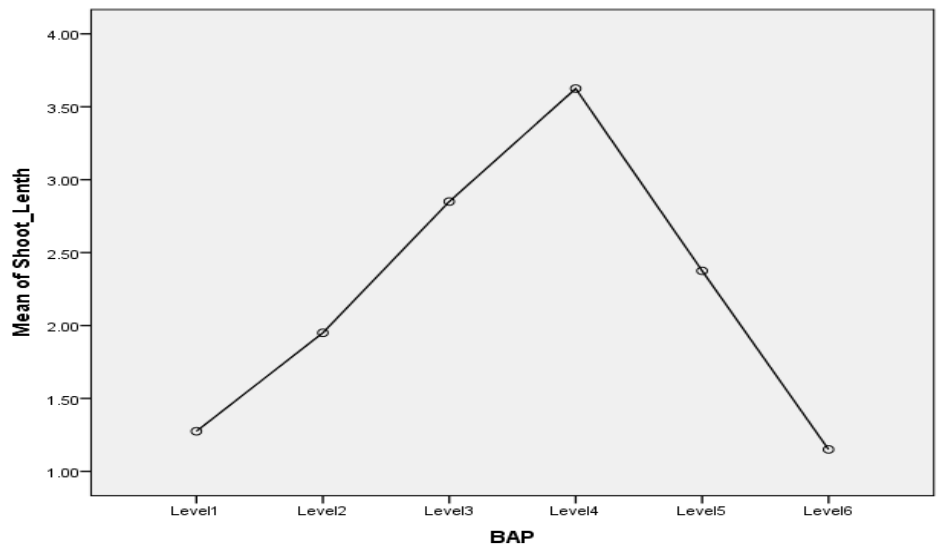

Fig 2: Effects of Phytohormones (Level 1 to level 6 is the different concentration of BAP 0.5 to 3.0 $\mathrm{mg} / \mathrm{l}$ and kinetin 0.5 to $2.5 \mathrm{mg} / \mathrm{l})$ on shoot multiplication of $N . j a t a m a n s i$ 
In vitro Root Formation: Various concentrations with the combination of auxin and cytokinin were used to generate roots in plants $1 / 2$ strength of the MS medium. In the different type of concentration NAA was approximately greater result than the concentration of IAA and IBA for rooting. The cytokinin and auxin (BAP+ NAA) appear Best rooting was performed in the concentration $1.5 \mathrm{mg}$ NAA and $1.0 \mathrm{mg}$ BAP in half strength of MS medium (Table 3) and the highest number roots per micro shoots were, $10.00 \pm 0.82$ which take only 12-16 days for initiation of root primordial with average root length $3.53 \pm$ $0.17 \mathrm{~cm}$ (Janhiv Rawat et al, 2015).

Table 3: Effect of different concentrations of 6-benzyl amino purine (BAP) and Napthylene acetic acid (NAA) in MS medium for root induction from regenerated shoots of $N_{\text {.jatamansi. }}$

\begin{tabular}{cccccc}
\hline S.N & $\begin{array}{c}\text { Ms mediun } \\
\text { NAA+BAP Mg/L }\end{array}$ & $\begin{array}{l}\text { Percentage } \\
\text { of } \\
\text { Responses }\end{array}$ & $\begin{array}{l}\text { Days taken to } \\
\text { root } \\
\text { formation }\end{array}$ & $\begin{array}{l}\text { No. of Shoot per } \\
\text { explant } \\
\text { (Mean +SE) }\end{array}$ & $\begin{array}{l}\text { Average length (Mean } \\
\text { +SE) }\end{array}$ \\
\hline 1. & $0.0+0.0$ & 0.00 & 0.00 & 0.00 & 0.00 \\
2. & $0.5+0.5$ & 20 & $14-18$ & $2.00 \pm 0.41$ & $1.43 \pm 0.09$ \\
3. & $1.0+0.5$ & 40 & $12-16$ & $4.50 \pm 0.65$ & $2.30 \pm 0.16$ \\
4. & $1.5+1.0$ & 70 & $10-14$ & $10.00 \pm 0.82$ & $3.53 \pm 0.17$ \\
5. & $2.0+1.5$ & 60 & $10-14$ & $8.50 \pm 1.04$ & $3.60 \pm 0.09$ \\
6. & $2.5+2.0$ & 40 & $12-15$ & $3.75 \pm 0.48$ & $2.28 \pm 0.11$ \\
7. & $3.0+2.5$ & 30 & $15-18$ & $1.25 \pm 0.25$ & $1.30 \pm 0.09$ \\
\hline
\end{tabular}

10 replicates/analysis; frequently thrice, Means are determine by the Duncan's multiple range tests at the expressive level of $5 \%$

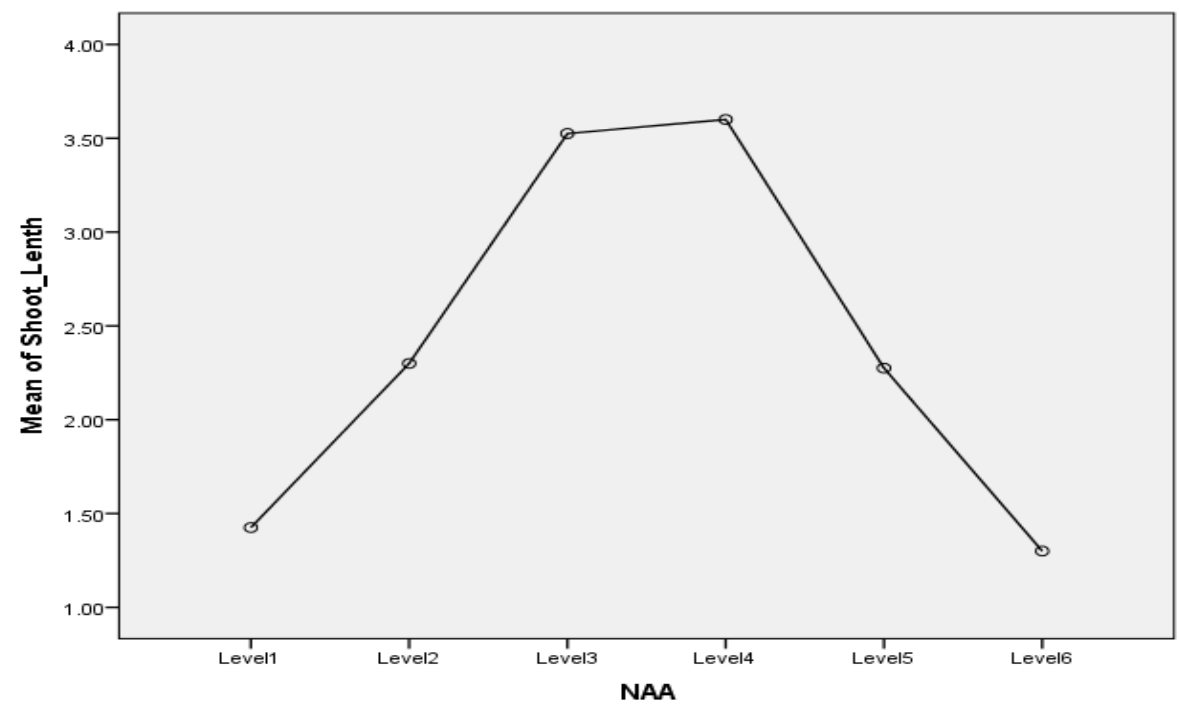

Fig 3: Effects of Phytohormones (Level 1 to level 6 is the different concentration of BAP 0.5 to $3.0 \mathrm{mg} / \mathrm{l}$ and NAA 0.5 to $2.5 \mathrm{mg} / \mathrm{l}$ ) on rooting of $N$.jatamansi 


\section{Acclimatization and Establishment of Plants}

in Soil: After rooting in N.jatamansi the root forming plant were carefully pull out from the culture medium and then medium washed from the roots with distilled water, then moves to smaller pots consist of a mixture of coco peat + garden soil + sand $(2: 2: 1 ; \mathrm{v} / \mathrm{v} / \mathrm{v})$. Afterwards 1214 days they moved from the pots to the field for promote growth for 10-15 days and spraying with water 2 days ( Jasari et al., 1999 and Shiragi et al., 2008).

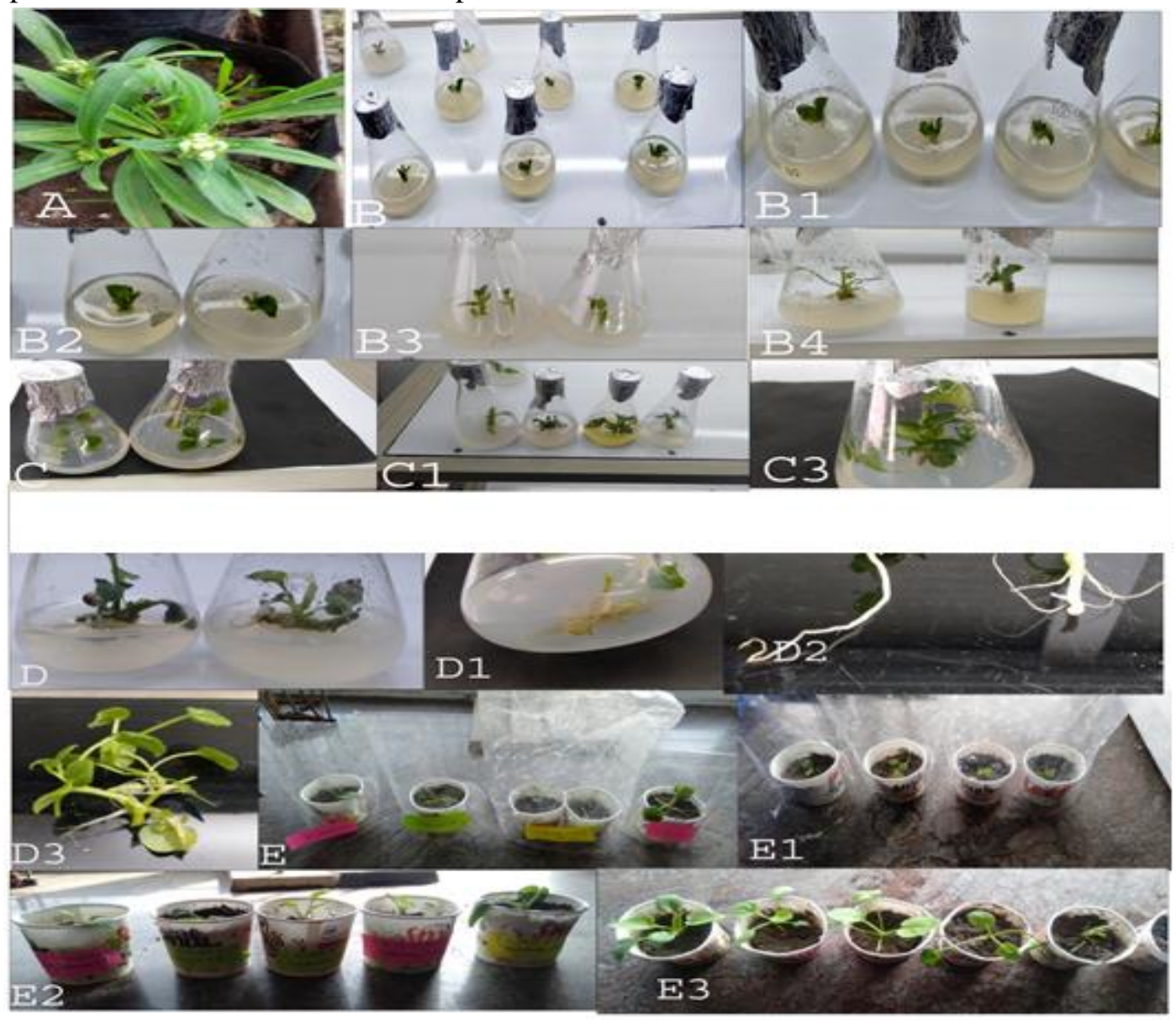

Fig 4: In vitro regeneration from nodal explants and shoot tip of Nardostachys jatamansi.

Nardostachys jatamansi from which nodal explants were taken (A). B. Shoots regenerated from shoot tip A. and nodal explant on MS medium supplemented with BAP, IBA(B-B4). C Multiple shoot formed on MS medium fortified with BAP and Kn after first subculture(C-C3) E. Roots produced on in vitro shoots grown on half strength MS medium(D-D3) G. Hardening of rooted plants coco peat, garden soil, sand 2:2:1 in mixture(E-E3).

\section{Abbreviations}

BAP - 6-Benzylaminopurine, KN - Kinetin, NAA - Naphthalene Acetic Acid, IBA - Indole-3-butyric acid, MS Murashige and Skoog medium, IAA - Indole-3-acetic acid, PVP - Poly-vinyl-pyrrolidone, RH - Relative Humidity 


\section{Discussion}

Plant tissue culture techniques for ornamental, medicinal as well as herbaceous plants have been well established. In vitro propagation technique is a powerful tool for plant germplasm conservation hence tissue culture is the only rapid process for the mass propagation of plants. The ability to generate plants directly for explants is fundamental to clonal multiplication of elite germplasm via micropropagation (Ignacimuthu et al, 1997).

Season of collection of explants is one of the most important factors in the establishment and growth of in vitro cultures. Maximum shooting and increase in length took place in explants after 12 to 16 days of incubation when treated with $\mathrm{BAP}+\mathrm{IBA}$ at the different concentration. The best response in shoot induction, with maximum shoot elongation $7.50 \pm 0.29$ with average length of the shoots $2.77 \pm 0.09 \mathrm{~cm}$ was obtained using 2.0mg/l 6-benzyl amino purine (BAP) in combination with $1.5 \mathrm{mg} / \mathrm{l}$ Indole butyric Acid (IBA). Different concentration of BAP and Kinetin was used for shoot multiplication. BAP and kinetin was found to be most effective cytokinin in inducing multiple shoot formation. The best response occurs in the M.S. medium with a lower level of BAP (2.0 $\mathrm{mg} / \mathrm{l})$ and kinetin $(1.5 \mathrm{mg} / \mathrm{l}$ ) for shoot multiplication and half strength $1 / 2$ of M.S. medium is with the concentration of NAA $(1.5 \mathrm{mg} / \mathrm{l})$ and BAP $(1.0 \mathrm{mg} / \mathrm{l})$ is very effective to produce root in plants. A reproducible protocol is developed for the regeneration of complete plants from nodal segments containing axillary buds. The growth and development was remarkably affected by growth regulator type and concentration as described in the protocol.

\section{Conclusion}

In vitro clonal propagation technique is the greater tool for propagation as it establishes the genetic stability and disease resistance clones of plants and prevents diversity in the cultures. The current investigation appearance a promising, large number plants, productive, speedy and cost-effective in-vitro propagation protocol in N.jatamansi through proliferation shoot formation. The instant protocol is smooth and finest as induction of shoots, multiple shoots, rooting is achievable on MS medium with different concentration and combination of growth phytohormone (Auxin and cytokinin) .This study can be utilized for economic in vito propagation and protection of this important, highly threatened medicinal plant.

Acknowledgement: We are thankful to Shri Guru Ram Rai University for the support and guidance.

\section{References}

Airi S, Rawal RS, Dhar U, Purohit AN (2000). Assessment of availability and habitat preference of jatamansi- a critically endangered medicinal plant of west 
Himalaya. Current Science 79(10): 14671470.

Alam F, Biswal PK, Kumar R, Chaudhari VK (2016). A Phytochemical and Pharmacological Review on Nardostachys jatamansi DC. International Journal of Current Trend in Pharmaceutical Research 4(2):115-118.

Bakhru HK (2009). Natural home remedies for common ailments. India (New Delhi), Orient Paperbacks.

Chandra B, Palni LMS, Nandi SK( 2006). Propagation and conservation of Picrorhiza kurrooa Royle ex Benth. An endangered Himalayan medicinal herb of high commercial value. Biodiversity Conservation 15:2325-2338.

Chopra IC, Jamwal KS, Khajuria BN (1954). Pharmacological action of some common essential oil bearing plant used in indigenous medicine. Part II, Pharmacological action of Alpinia galangal, Pistacia integrima, Piper betel and Nardostachys jatamansi. Indian Journal of Medical Research 42(3): 385388.

Das S, Jha TB, Jha S (1996). Strategies for improvement of Cashewnut through Tissue Culture. In: Plant Tissue Culture. Islam AS (ed.) Oxford and IBH Publishing Co. Pvt. Ltd 1-7.

Devnath M, Malik CP, Bisen PS (2006). Micropropagation: a tool for the production of high quality plant-based medicines. Current pharmaceutical biotechnology 7(1): 33-49.

Disket J, Gupta RK, Mann S (2012). A Review on Spikenard (Nardostachys jatamansi DC)-An 'Endangered' Essential Herb of India. International Journal of Pharmaceutical Chemistry 2(3):52-60.

Dodds JH (1991). In vitro methods for conservation of plant genetic resources. Book, published by Chapman and Hall, London.

Evans WC (2008) . Pharmacognosy. WB Saunders publishers, 15th Edition 10-12.

Gaurav N, Juyal P, Tyagi M, Chauhan N, Kumar A (2018) . A review on in vitro propagation of medicinal plants. Journal of pharmacognosy and phytochemistry 7(6):2228-2231.

George EF (1993) .Plant propagation by tissue culture. Part 1. TheTechnology. Exegetics Ltd., Edington, wilts, England 89-91.

George EF, Sherrington PD (1984). Plant propagation by tissue culture. Handbook and directory of commercial laboratories. Exegenetics Ltd., Basingstoke, Hants, England 444-447.

Ignacimuthu S (1997) Plant Biotechnology, Oxford and IBH publishing Co. Pvt. Ltd 180.

Janhvi R, Aakriti B, Kanchan K, Manoj R, Balwant R, Ashok KD, Ranjana KN, Ajay T Anup C (2017). RAPD based 
genetic fidelity analysis of in vitro regenerated plants of Nardostachys jatamansi. International Journal on Biological Sciences 8 (2) : 141-147.

Jasari YT, Kannan VR, Remakanthan A, George MM (1999). Ex vitro survival of in vitro derived banana plants without greenhouse facilities. Plant Tissue Cult 9(2).

Khosh-Khui M Sink KC (1982). Micropropagation of new and old world species. J. Hort. Sci 57: 315-319.

Lal N, Ahuja PS, Kukreja AK, Pandey B (1988). Clonal propagation of Picrorhiza kurrooa Royle ex Benth. By shoot tip culture. Plant Cell Rep 7: 201-205.

Leifert C,Waites WM (1992) . Bacterial growth in plant tissue culture media.J Appl Bacteriol 72: 460- 466.

Monokesh KS , Mehedi H, Shamima N, Mostofa J , Mamun-Or-Rashid ANM, Biplab D (2013). In vitro sterilization protocol for micropropagation of Achyranthes aspera L. node. International Research Journal of Biotechnology 4(5), 89-93.

Mulliken TA( 2000). Implementing convention of international trade in endangered species of wild flora and fauna (CITES) for Himalayan medicinal plants Nardostachys grandiflora and Picrorhiza kurroa. Traffic bull (18): 63-72.
Nadkarn AK (1954). Indian materia medica vol.1,3 ${ }^{\text {rd }}$ Ed.,popular book depot,Bombay 840-842.

Nautiyal BP, Chauhan RS, Prakash V, Purohit H, Nautiyal MC ( 2003). Population studies for the evaluation of germplasm and threat status of the alpine medicinal herb, Nardostachys jatamansi. Plant Genet Resour Newsl 136:34-39.

Shiragi H, Baque M ,Nasiruddin K (2008). Eradication of Banana Bunchy Top Virus and Banana Mosaic Virus from Infected Plant of Banana cv. Amritasagar. Through Meristem Culture. Department of Horticulture, Bangladesh Agricultural University, South Pacific Studies. 29, No.1

Staba EJ, Seabrook JEA (1980). Laboratory Culture: Plant Tissue Culture as a Source of Biochemicals. Boca Raton; CRC press $1-20$.

The Wealth of India (1997) .An Encyclopedia of India's Raw Materials Resources. ISBN: 81-85038-00-7.

Thorat RM, Kamble SS, Kadam VJ , Jadhav VM (2009). Herbal anxiolyte: Nardostachys jatamansi. Journal of Pharmacy Research 2(8): 1208-1211.

Vijay K, Purohit RS, Harish C, Andola P, Prasad MC Nautiyal AR (2012). Nardostachys jatamansi DC:Conservation, multiplication and policy issues, International Journal of 
Phytomedicines and Related Industries 4(3): 162-166.

Vijay KP, Chauhan RS, Harish C, Andola P, Prasad MC, Nautiyal AR (2012). Nardostachys jatamansi DC:

Conservation, multiplication and policy issues. Medicinal plants 4(3): 162-166.

Wetzsteinand HY (2000). Anatomy of plant cells. In: R.e. spier (editor) Encyclopedia of Cell Technology 24-31.

Yang YC (1996). Tibetan Materia medica, Qinghai people's presses Qinghai, china. 